\title{
INTENSIVE CARE UNIT MANAGEMENT OF SARS- COV-2 PATIENTS: A NARRATIVE REVIEW
}

\author{
Taimoor Hassan ${ }^{1,2}$, Sana Saeed ${ }^{2,4}$, Sidra Naseem², Fiza Saleem ${ }^{3}$ \\ ${ }^{1}$ School of Pharmacy \& School of Medicine, Changzhou University, Jiangsu, China, ${ }^{2}$ Department of Health \\ Professional Technologies \& ${ }^{3}$ University Institute of Medical Laboratory Technology, The University of Lahore, \\ Lahore, Pakistan, ${ }^{4}$ Department of Pharmaceutical Sciences, Tianjin University, Tianjin, China
}

\begin{abstract}
The 2019 Coronavirus disease is a public health emergency of international concern (PHEIC). COVID-19 causes acute respiratory distress syndrome (ARDS) in certain individuals. In such individuals, non-invasive and invasive ventilation methods are used to treat ARDS. Non-invasive ventilation approaches must be used initially before introducing intrusive mechanical ventilation techniques. Non-invasive methods used in the therapy of COVID-19 associated ARDS include high-flow nasal cannula, bi-level positive air pressure, and helmet ventilation. Before employing any of these non-invasive methods, the risk of viral aerosol transmission to healthcare and paramedical personnel must be considered. When non-invasive procedures are used, the load on hospital ventilatory equipment can be reduced. If at all possible, avoid intubating the patient too soon. The clinical appearance of the patient, as well as vital indicators such as oxygen saturation and respiratory rate must be evaluated on frequent basis in order to determine whether the patient requires ventilation. In COVID-19 patients, the judicious application of non-invasive and invasive breathing methods can minimize the risk of death from ARDS.
\end{abstract}

KEYWORDS: Acute Respiratory Distress Syndrome; Continuous Positive Airway Pressure; COVID-19 Virus; Health Hazards; Hypoxia; Intensive Care Units; SARS-CoV-2; Personal Protective Equipment; Real-Time PCR; Oxygen Saturation.

Cite as: Hassan T, Saeed S, Naseem S, Saleem F. Intensive care unit management of SARS-CoV-2 patients: a narrative review [review article]. Gomal J Med Sci 2021 Oct-Dec; 19(4):152-6. https://doi.org/10.46903/gjms/19.04.1024

\section{INTRODUCTION}

COVID-19, a novel illness caused by the SARSCoV-2 virus, has appeared since December 2019. It's a brand-new corona virus. The instances of this sickness initially surfaced in the city of Wuhan, China at the end of 2019. ${ }^{1}$ The disease quickly spread around the world and was labeled as COVID-19 Pandemic by WHO on March 11, 2020. Fever, dry cough, tiredness, and dyspnea are the most frequent symptoms of the disease. Uncommon symptoms include loss of taste and smell, diarrhea, conjunctivitis, sore throat and headache. ${ }^{2}$ The virus spreads from the infected individual nasal and oral routes by tiny aerosol particles when the affected

\section{Corresponding Author:}

Taimoor Hassan

Post-graduate Scholar

School of Pharmacy \& School of Medicine

Changzhou University, Jiangsu, China

E-mail: taimoorhassan408.th@gmail.com

$\begin{array}{ll}\text { Date Submitted: } & 04-08-2021 \\ \text { Date Revised: } & 23-09-2021 \\ \text { Date Accepted: } & 29-09-2021\end{array}$

individual coughs, sneezes, speaks or breathes hard, particularly congested interior places. The most common techniques used to control the spreading of the virus include social isolation, frequent handwashing, and the use of face masks. Real-time PCR (sample collected by nasal swab) and serology testing for COVID-19 antibody are the two major diagnostic procedures for COVID-19 confirmation. ${ }^{3}$ Chest X-ray would typically demonstrate bilateral enlarged interstitial mar-kings. On computerized tomography, ground glass opacity is by far the most prevalent radiological finding. ${ }^{4}$ Most patients have lymphocytopenia. Patients over the age of 65 years who have comorbidities such as hypertension and diabetes are more prone to become critically sick. The most prevalent consequence in COVID-19 patients admitted to the ICU is acute hypoxemic respiratory failure from ARDS, followed by sepsis, shock, myocardial dysfunction, and acute renal injury. ${ }^{8}$ COVID-19 patients are managed in the ICU utilizing various methods, including continuous positive airway pressure (CPAP), bi-level positive air pressure (BIPAP), Helmet ventilation, invasive mechanical ventilation, and in certain cases, extracorporeal membrane oxygenation (ECMO). ${ }^{5,6}$ 


\section{METHODOLOGY}

This narrative review was conducted in School of Pharmacy \& School of Medicine, Changzhou University, Jiangsu, China from February 2021 to July 2021. In order to access the intensive care unit management of SARS-CoV-2 patients, this review analyzed articles published for the period from January 2020 to July 2021 in both local and foreign journals. The main question of this paper was the intensive care unit management of SARS-CoV-2 patients. To answer this question, different keywords; COVID-19; Acute Respiratory Distress Syndrome, COVID-19 pandemic, COVID-19 therapies and Health Hazards were separately and in combination searched in different electronic databases such as PubMed, CINAHL, Web of Science, Scopus, eMedicine and HEC digital library. The inclusion criteria of the articles were based on the intensive care unit management of SARS-CoV-2 patients, published from January 2020 to June 2021. Articles with irrelevant information, copyright and lacking the full text were not included in this study. For this research, 51 publications were chosen, from which 26 articles were screened following an abstract review and the removal of any duplications. In the last round, 25 publications were chosen for further study. All of these pieces were written in English.

\section{DISCUSSION}

The Progression of Disease: The disease typically progresses in three stages.

Stage 1: It is characterized by fever $>99.6$ of, diarrhea, headache and dry cough. Laboratory findings include elevated prothrombin time, lymphopenia, elevated D-Dimer and LDH (mild). ${ }^{7}$

Stage 2: It is characterized by breathlessness and hypoxia ( $\mathrm{PaO} 2 / \mathrm{FiO} 2200 \mathrm{mgHg}$ ). Laboratory findings include normal-to-high procalcitonin levels, transaminitis, and aberrant chest imaging. ${ }^{8}$

Stage 3: It is characterized by ARDS, SI-RS/ shock, and cardiovascular arrest. Laboratory findings include elevated inflammatory markers (CRP, LDH, IL-6, D-dimer, ferritin), NT-proBNP and troponin. ${ }^{7,8,9}$

Remdesivir, steroids and convalescent plasma transfusion are all potential treatments for the illness. During the early stages of the illness, efforts should be undertaken to decrease immunological suppression. Human immunoglobulins, IL-2 inhibitors, IL-6 inhibitors, and JAK inhibitors are all possible treatments for the disease's late stage. ${ }^{10}$

3.2 C-ARDS: COVID-ARDS (C-ARDS) is an abbreviation for COVID-19 associated acute respiratory distress syndrome. With the passage of time in this pandemic, clinicians treating COVID-19 cases throughout the world have made a new observation regarding the peculiarity of COVID-19-related ARDS. ARDS is characterized as respiratory failure that oc- curs within a week of a known clinical assault and is accompanied by bilateral opacities on chest imaging and reduced lung compliance. Mechanical ventilation with greater PEEP modulation is commonly used in management. The idea that C-ARDS is unique is currently being debated. COVID-19 causes vascular injury, which destroys the capillary epithelial barrier by directly damaging epithelium and indirectly hurting endothelium via the activated immune system. ${ }^{11}$ This is further backed by evidence showing that individuals at high risk of vascular illnesses, such as hypertensives, hyperlipidemics and diabetics, have a higher chance of developing COVID-related severe disease. Patients with ARDS have severe hypoxemia and decreased lung compliance, which are treated by mechanical ventilation and lowering PEEP to prevent lung collapse. COVID-19 individuals are likewise hypoxemic in the early stages, but have more compliant lungs than non-COVID-19 ARDS patients. COVID-19 related ARDS might be characterized by decreased lung recruitability and compliance in some individuals. ${ }^{12}$ This is critical in the decision to use mechanical ventilation due to the shortage of resources in this continuing pandemic, particularly in poor nations. C-ARDS has two phenotypes, indicated by the letters $L$ and $H$ for low and high, respectively. Low phenotype lungs have low elastance, recruit-ability and lung weight, whereas high phenotype lungs have high elastance, lung weight, and recruitability. As a result, the high type requires earlier intubation and mechanical breathing support than the low type. Those who typically present with a low phenotype may or may not progress when compared to patients with a high phenotype. However, further information is required before this categorization can be made. ${ }^{13,14}$

3.3 COVID-19: Oxygen Therapy Algorithm Escalation: The COVID-19 escalation of oxygen therapy algorithm has a target oxygen saturation of $92-96 \%$. Low Flow Nasal Cannula (LFNC) 1-6 L and HHHFNC are two options ( 2 hours trial). If oxygen saturation is persistently $<92 \%$, pulse rate is $<30, \mathrm{pH}$ is greater than 7.2, minor respiratory distress, and excellent mental status/ airway protection; escalate to helmet ventilation. Mechanical ventilation is recommended if helmet ventilation fails. If a patient exhibits these signs such as $\mathrm{SaO} 2<92 \%$, pulse rate $>30, \mathrm{pH}>$ 7.2, poor mental status/ airway protection, intolerance, emesis, and profuse secretions; proceed to mechanical ventilation. ${ }^{15}$

3.4 Helmet Ventilation Therapy: Helmet ventilation is a method of non-invasive ventilation. It is made up of a transparent helmet that covers the head and face, as well as a soft collar around the neck. It is most commonly used with a ventilator, although it may also be used with a V-60 BIPAP machine. It is more pleasant and well tolerated by patients due to its non-invasive nature, with fewer problems. Further- 
more, they will have more movement and will require less sedatives and intrusive mechanical ventilation. The oxygen flowmeter is opened and the helmet is linked to a ventilator/ Bipap. PEEP is set to $5 \mathrm{cmH} 2 \mathrm{O}$ and $\mathrm{FiO} 2$ (fraction of inspired oxygen) is set to $60 \%$. If the effort of breathing and $\mathrm{PO} 2$ do not improve after 15-30 minutes of reassessment, raise the PEEP to $10 \mathrm{~cm} \mathrm{H} 2 \mathrm{O}$ and titrate oxygen to retain saturation over 92 percent. Proceed to invasive mechanical ventilation if work of breathing rises and/ or oxygen saturation does not improve. ${ }^{16}$

According to a study, patient who use a helmet ventilator have a significantly lower rate of endotracheal tube intubation than those who use an oxygen face mask. ${ }^{17}$

It also indicated that using helmet ventilation lowers the requirement for endotracheal intubation by around $20-30 \%$ and resulting in a nearly $80 \%$ reduction in mortality in COVID-19 intubated patients. ${ }^{18}$

3.5 HHHFNC Therapy: HHHFNC is an acronym for heated humidified high flow nasal cannula. Except where early intubation is indicated, it is largely accepted within COVID-19 recommendations for patients with low blood oxygen saturation and ARDS. Improved oxygenation, high flow rates (40-60 L/min), generation of positive nasopharyngeal/ tracheal airway pressure, decreased anatomic dead space due to upper airway washout, decreased metabolic cost of breathing/ reduced carbon dioxide generation, improved work of breathing, inspired gas is preconditioned (heated and humidified), and better secretion clearance are some of the advantages of HHHFNC. To minimize labor of breathing, it aims for the maximum flow tolerated by the patient while slowly titrating $\mathrm{FiO} 2$ to reach the required $\mathrm{SpO} 2$. Set the temperature to the patient's preference. ${ }^{19,20}$

COVID-19 transmission to hospital workers has been a major problem in the care of critically ill patients. If the patient wears a mask and the room is under negative pressure, aerosol transfer in HHHNFC during coughing and sneezing appears to be low. ${ }^{21}$

3.6 Awake Prone Position: In COVID-19 individuals, low oxygen saturation is a frequent symptom. Proning has proven to be an effective method for managing COVID-19 ICU patients. It has been proven to help improve oxygenation and V/Q mismatch in ventilated ARDS patients. It also lowers the risk of lung damage caused by ventilation. Proning when awake increases oxygenation by aerating the non-aerated dorsal lung regions. It also improves $\mathrm{CO} 2$ removal. In patients with High Flow Nasal Cannula (HFNC), early use of the Awake Prone Position has been proven to reduce the need for intubation. ${ }^{22}$

3.7 ECMO Therapy: ECMO is an acronym for extracorporeal membrane oxygenation. Extracorporeal refers to something that exists outside of the body. It's a machine that oxygenates the blood while removing carbon dioxide from the body. The heart-lung by-pass device used in open-heart surgery is comparable to the ECMO system. It functions as a substitute for a lung. ${ }^{23}$ It pumps and oxygenates a patient's blood outside of the body, freeing up the heart and lungs. When a patient has significant respiratory distress, such as that seen in critically sick COVID-19 patient, extracorporeal membrane oxygenation is indicated. The critically ill covid-19 patients' failure to oxygenate their blood can be fatal. In-hospital mortality was linked to the use of ECMO for circulatory support. As a result, the efficacy of ECMO in reducing in-hospital mortality is still in question. ${ }^{24}$

3.8 Complications of ECMO: ECMO is accomplished in severely ill Covid-19 patients using a complex equipment that oxygenates and maintains blood flow. ECMO has its own set of risks, which vary according on the severity of the patient's underlying condition and the length of time they are on it. Cannulation-related problems, such as hemorrhages account for the vast majority of the first difficulties. Then there are renal complications, which generally manifest as acute kidney damage due to vascular causes. With IV thrombosis, a coagulation profile that is out of whack is common. Infections can also be caused from ECMO therapy, such as bacterial pneumonia, aspiration pneumonia, and other infections caused by contaminated-machines. There have also been reports of neurological problems such as delirium and cerebrovascular damage. Other vascular abnormalities, particularly following removal from ECMO support, such as aneurysms and AV fistulas are also found, as COVID-19 is recognized for its pro-coagulative properties. ${ }^{21-25}$

\section{FUTURE PROSPECTS AND LESSONS FOR US}

1. Because of viral aerosolization, nebulization should be avoided.

2. To reduce exposure, the use of automated CPR for cardiac arrests should be advocated.

3. Responsible use of personal protective equipment (PPE) including face shields, masks etc. should be mandatory for all staff.

4. Healthcare providers should prioritize self-care.

5. Healthcare providers, such as physicians and nurses, should be given every opportunity to decrease both mental and physical burnout, as excessive burnout promotes system inefficiencies.

6. To reduce the exposure, proper utilization of intubation and extubation devices is highly devised.

7. Only experts should be allowed to do specific intubations.

8. As a precautionary measure, IV pumps, CRRT devices, and ventilator controls should be relocated out of patients' rooms. 


\section{CONCLUSION}

Many techniques are being utilized to save the lives of critically ill COVID-19 patients in the intensive care units. Attempts are being undertaken to manage patients with ARDS, beginning with low flow and progressing to high flow, non-invasive methods, and eventually invasive mechanical ventilation. Proning, particularly conscious proning, and early neuromuscular paralysis are beneficial. If accessible, ECMO can serve as a bridge to recovery or lung transplantation with a reasonable chance of life.

\section{REFERNECES}

1. Huang $\mathrm{C}$, Wang $\mathrm{Y}$, Li X, Ren L, Zhao J, Hu Y, et al. Clinical features of patients infected with 2019 novel coronavirus in Wuhan, China. Lancet 2020 Feb 15;395 (10223):497-506. https://doi. org/10.1016/S0140-6736(20)30183-5

2. Ai T, Yang Z, Hou H, Zhan C, Chen C, Lv W, et al. Correlation of chest CT and RT-PCR testing in coronavirus disease 2019 (COVID-19) in China: a report of 1014 cases. J Radiol 2020 Feb 26:200642. https://doi.org/10.1148/radiol.2020200642

3. Shi H, Han X, Jiang N, Cao Y, Alwalid O, Gu $\mathrm{J}$, et al. Radiological findings from 81 patients with COVID-19 pneumonia in Wuhan, China: a descriptive study. Lancet infect Dis $2020 \mathrm{Apr}$ 1;20(4):425-34. https://doi.org/10.1016/S14733099(20)30086-4

4. Hassan T, Khan MS, Saeed S. How Pakistan is combating COVID-19 pandemic?. J Liaquat Uni Med Health Sci 2021 Jun 29;20(2):81-2.

5. Guan WJ, Ni ZY, Hu Y, Liang WH, Ou CQ, He $\mathrm{JX}$, et al. Clinical characteristics of coronavirus disease 2019 in China. New Eng J Med 2020 Apr 30;382(18):1708-20. https://doi.org/10.1056/ NEJMoa2002032

6. Wang D, Hu B, Hu C, Zhu F, Liu X, Zhang J, et al. Clinical characteristics of 138 hospitalized patients with 2019 novel coronavirus-infected pneumonia in Wuhan, China. JAMA 2020 Mar 17;323(11):1061-9. https://doi.org/10.1001/ jama.2020.1585

7. Liu KC, Xu P, Lv WF, Qiu XH, Yao JL, Jin-Feng G. CT manifestations of coronavirus disease-2019: a retrospective analysis of 73 cases by disease severity. Eur J Radiol 2020 Mar 12:108941. https:// doi.org/10.1016/j.ejrad.2020.108941

8. Arentz M, Yim E, Klaff L, Lokhandwala S, Riedo FX, Chong M, et al. Characteristics and outcomes of 21 critically ill patients with COVID-19 in Washington State. JAMA 2020 Apr 28;323(16):1612-4. https://doi.org/10.1001/jama.2020.4326

9. Han W, Quan B, Guo Y, Zhang J, Lu Y, Feng G, et al. The course of clinical diagnosis and treatment of a case infected with coronavirus disease 2019. J Med Virol 2020 May;92(5):461-3. https://doi. org/10.1002/jmv.25711
10. Thomas-Rüddel $D$, Winning J, Dickmann P, Ouart $D$, Kortgen A, Janssens U, et al. Coronavirus disease 2019 (COVID-19): update for anesthesiologists and intensivists March 2020. Der Anesthetist 2020 Mar 24;45(1):3-9. https://doi.org/10.1007/ s00101-020-00760-3

11. Siddiqi HK, Mehra MR. COVID-19 illness in native and immunosuppressed states: A clinical-therapeutic staging proposal. J Heart Lung Transplant 2020 May;39(5):405-11. https://doi.org/10.1016/j. healun.2020.03.012

12. Chen L, Xiong J, Bao L, Shi Y. Convalescent plasma as a potential therapy for COVID-19. Lancet Infect Dis 2020 Apr 1;20(4):398-400. https://doi. org/10.1016/S1473-3099(20)30141-9

13. Sanders JM, Monogue ML, Jodlowski TZ, Cutrell J-B. Pharmacologic treatments for coronavirus disease 2019 (COVID-19): a review. JAMA 2020 May 12; 323(18):1824-36. https://doi.org/10.1001/ jama.2020.6019

14. Rizk JG, Kalantar-Zadeh K, Mehra MR, Lavie CJ, Rizk Y, Forthal DN. Pharmaco-immunomodulatory therapy in COVID-19. Drugs 2020 Jul 21:1-26. https://doi.org/10.1016/j.drudis.2020.11.025

15. Mangalmurti NS, Reilly JP, Cines DB, Meyer NJ, Hunter CA, Vaughan AE. COVID-19-associated acute respiratory distress syndrome clarified: a vascular endotype?. Am J Respir Crit Care Med 2020 Sep 1;2020(5):750-3. https://doi. org/10.1164/rccm.202006-2598LE

16. Grasselli $G$, Tonetti $T$, Protti A, Langer $T$, Girardis $M$, Bellani G, et al. Pathophysiology of COVID-19-associated acute respiratory distress syndrome: a multicentre prospective observational study. Lancet Respir Med 2020 Aug 27;201(12):1324-31. https://doi.org/10.1016/S2213-2600(20)30370-2

17. Pan C, Chen L, Lu C, Zhang W, Xia JA, Sklar MC, et al. Lung recruitability in COVID-19-associated acute respiratory distress syndrome: a single-center observational study. Am J Respir Crit Care Med 2020 May 15;201(10):1294-7. https://doi. org/10.1164/rccm.202003-0527LE

18. Fan E, Beitler JR, Brochard L, Calfee CS, Ferguson ND, Slutsky AS, et al. COVID-19-associated acute respiratory distress syndrome: is a different approach to management warranted?. Lancet Respir Med 2020 Aug;8(8):816-21. https://doi. org/10.1016/S2213-2600(20)30304-0

19. Sardesai I, Grover J, Garg M, Nanayakkara PW, Di Somma S, Paladino L, et al. Short-term home oxygen therapy for COVID-19 patients: The COVID-HOT algorithm. Fam Med Prim Care Rev 2020 Jul;9(7):3209. https://doi.org/10.4103/ffmpc. jfmpc_1044_20

20. Thompson AE, Ranard BL, Wei Y, Jelic S. Prone positioning in awake, nonintubated patients with COVID-19 hypoxemic respiratory failure. JAMA Intern Med 2020 Nov 1;180(11):1537-39. https:// doi.org/10.1001/jamainternmed.2020.3030 
21. Caputo ND, Strayer RJ, Levitan R. Early self-proning in awake, non-intubated patients in the emergency department: a single ED's experience during the COVID-19 pandemic. Acad Emerg Med 2020 May;27(5):375-8. https://doi.org/10.1111/ acem. 13994

22. Cohen D, Wasserstrum Y, Segev A, Avaky C, Negru L, Turpashvili N, et al. Beneficial effect of awake prone position in hypoxemic patients with COVID-19: case reports and literature review. Intern Med J 2020 Aug;50(8):997-1000. https:// doi.org/10.1111/imj.14926

23. Xu Q, Wang T, Qin X, Jie Y, Zha L, Lu W. Early awake prone position combined with high-flow nasal oxygen therapy in severe COVID-19: a case series. Crit Care 2020 Dec;24(1):1-3. https://doi. org/10.1186/s13054-020-02991-7

24. Wang K, Zhao W, Li J, Shu W, Duan J. The experience of high-flow nasal cannula in hospitalized patients with 2019 novel coronavirus-infected pneumonia in two hospitals of Chongqing, China. Ann Intensive Care 2020 Dec;10;(11):656-62. https://doi.org/10.1186/s13613-020-00653-z

25. Xia JG, Zhao JP, Cheng ZS, Hu Y, Duan J, Zhan QY. Non-invasive respiratory support for patients with novel coronavirus pneumonia: clinical efficacy and reduction in risk of infection transmission. Chin Med J 2020 May 5;133(9):1109-11. https:// doi.org/10.1097/CM9.0000000000000761

CONFLICT OF INTEREST

Authors declare no conflict of interest. GRANT SUPPORT AND FINANCIAL DISCLOSURE None declared.

\begin{tabular}{|c|c|}
\hline \multicolumn{2}{|c|}{$\begin{array}{l}\text { AUTHORS' CONTRIBUTION } \\
\text { The following authors have made substantial contributions to }\end{array}$} \\
\hline Conception or Design: & TH, SS \\
\hline Acquisition, Analysis or Interpretation of Data: & TH, SS, SN, FS \\
\hline Manuscript Writing \& Approval: & TH, SS, SN, FS \\
\hline
\end{tabular}
stricted use, distribution \& reproduction in any medium provided that original work is cited properly. 